\title{
Bericht über den 8. Internationalen Kongreß über Ernährung in Prag
}

\author{
Von K. LANG (Bad Krozingen)
}

Am 28. August bis 5. September 1969 fand in Prag unter dem Vorsitz von Prof. Dr. D. J. MAŠEK der 8. internationale Kongreß über Ernährung statt.

Das außerordentlich große Gebiet, das gegenwärtig in einer weiten Ausweitung begriffen ist und die intensive Forschung auf allen Teilgebieten machten es notwendig, das Gesamtgebiet in 8 Sektionen aufzugliedern:

1. Biochemie der Ernährung

(Vorsitzender K. LANG)

2. Die beim Wachstum und der Homöostase beteiligten Stoffwechselprozesse

(Vorsitzende H. MUNRo und WmDowsow)

3. Ernährung und Massenerkrankungen

(Vorsitzende H. GOUNELLE und J. MAŠEK)

4. Sekundäre Ernährungsstörungen

(Vorsitzender A. C. Frazer $\dagger$ )

5. Ernährungsstudien in Industrieländern und Entwicklungsländern

(Vorsitzende J. CRavioto und T. TACHEv)

6. Hygienische Gesichtspunkte bei der Ernährung

(Vorsitzende R. Truhaut und O. HöGL)

7. Bestimmung des Nährwertes von Lebensmitteln und Lebensmitteltechnologie

(Vorsitzende J. SHORMülleR und G. JaNICEK)

8. Optimale Bestimmungen zur Erzeugung von Lebensmitteln in der Landwirtschaft

(Vorsitzender K. BODA).

Außerdem hatte sich als 9. Sektion noch die International Society for Parenteral Nutrition

(Präsident H. C. MENG) angeschlossen.

In allen Sektionen wurden in Symposien durch zusammenfassende Vorträge und Diskussionen der neueste Stand der jeweiligen Gebiete erarbeitet.

$\mathrm{Zu}$ einer großen Anzahl von Kurzvorträgen wurden zahlreiche neue Ergebnisse auf den verschiedensten Teilgebieten vorgetragen.

Außerdem wurden in Round-Table-Gesprächen Brennpunkte der Forschung und des Interesses besonders ausgiebig diskutiert.

Die große Fülle der behandelten Themen macht es unmöglich, auf die einzelnen vorgetragenen oder in Diskussionen erarbeiteten Ergebnisse näher einzugehen.

Als einziger Punkt sei der Bericht über eine 71/2 Monate dauernde komplette parenterale Ernährung eines Patienten von D. A. CoAT hervorgehoben, der eine Reihe von interessanten Beobachtungen wie erstmalig gesicherten Nachweis des Bedarfs des Menschen an den essentiellen Fettsäuren nebst den klinischen Symptomen des Mangelsyndroms sowie analoge Befunde über den Zinkbedarf des Menschen enthielt.

Die großen Erfolge der parenteralen Ernährung, vor allem auch in der langfristigen Anwendung, die von vielen Vortragenden geschildert wurden, machen dieses Gebiet zu einem der Brennpunkte der medizinischen Ernährungsforschung.

Abschließend sei noch die mustergültige Organisation des Kongresses besonders hervorgehoben.

Der nächste internationale Ernährungskongreß soll 1972 in Mexico stattfinden. 